\title{
PROMOVENDO O DESENVOLVIMENTO PROFISSIONAL NA FORMAÇÃO DE PROFESSORES: A PRODUÇÃO DE HISTÓRIAS INFANTIS COM CONTEÚDO MATEMÁTICO
}

\section{Fostering professional development in teacher education: the creation of children's stories with mathematical content}

\author{
Rosa Maria Moraes Anunciato de Oliveira ${ }^{1}$ \\ Cármen Lúcia Brancaglion Passos ${ }^{2}$
}

\begin{abstract}
Resumo: As demandas ao trabalho docente envolvem o ensino e a aprendizagem de um rol de conceitos, procedimentos ou saber-fazer e atitudes. Os professores buscam atender a essas diferentes demandas. Nos cursos de formação contínua, professores em serviço revelam expectativas sobre utilização de materiais e solicitam atividades práticas aplicáveis no ensino. Tomamos, como objeto de investigação, a formação docente e sua relação com os materiais de ensino, sobretudo por esse tema ser freqüentemente relegado. Analisamos as contribuições da construção de livros com conteúdo matemático para o desenvolvimento profissional de professores. A criação de um material para ser utilizado na escola com seus alunos favoreceu tanto a resignificação de conteúdos específicos de matemática, como outras possibilidades de desenvolvimento profissional dos professores. A construção de materiais de ensino não pode ser vista como menor ou como capitulação ao tecnicismo pedagógico, deve ser concebida como etapa fundamental para a consecução dos objetivos educacionais.
\end{abstract}

Palavras-chave: Formação de professores. Histórias infantis e matemática. Material didático. Ensino de matemática.

\footnotetext{
Abstract: The demands of teachers' work involve the teaching and learning of a great variety of concepts, procedures and attitudes, which teachers seek to update. In continuous education courses, teachers have been showing that they have some expectations about the use of handling material and they have been asking for practical teaching activities. Our investigation is into teacher education and teachers' relationships with teaching material. We have analyzed how the creation of children's books with mathematical content has contributed to teachers' professional development. Creating material meant to be used with students has helped to bring both a new meaning to specific contents and other possibilities for professional development. The construction of teaching material must not be seen as something minor or as surrendering to pedagogical technicality; it must be regarded as a very important step in reaching the educational goals.

Keywords: Teacher education. Children's stories and mathematics. Didactic material. Mathematics teaching.

${ }^{1}$ Professora do Departamento de Metodologia de Ensino e do Programa de Pós-Graduação em Educação da Universidade Federal de São Carlos, UFSCar. <rosa@ufscar.br>

${ }^{2}$ Professora do Departamento de Metodologia de Ensino e do Programa de Pós-Graduação em Educação da Universidade Federal de São Carlos, UFSCar. <carmen@ufscar.br>

${ }^{1}$ Rua João Tonissi, 160

Jardim Hikare

São Carlos, SP

$13.564-440$

315

Ciência \&̊ Educação, v. 14, n. 2, p. 315-330, 2008
} 


\section{Introdução}

Nos momentos de crise social, como a que atravessamos atualmente, a sociedade se pergunta qual a função da escola e dos professores. Essa questão exigiria um exame rigoroso com muitas implicações epistemológicas e práticas na área da educação. Por isso, nos ateremos à demanda por um ensino significativo que procure atender às diferenças individuais, cognitivas e culturais. Um fato motivou essa investigação: a reiteração de experiências, em cursos de formação contínua, em que os professores em serviço revelam a expectativa de que a utilização de materiais manipuláveis no processo de ensino pode amenizar as dificuldades de aprendizagem dos alunos; ou solicitam atividades práticas, aplicáveis nas situações de ensino protagonizadas por eles. Essa expectativa nem sempre é atendida pelos formadores, sendo identificada, algumas vezes, como uma busca de soluções prontas, padronizadas, que não consideram o contexto e as individualidades. É possível sair desse impasse? Os formadores e os professores em serviço apresentam duas lógicas opostas? Que visão de educação defendem? Tomamos, como objeto, a formação docente e sua relação com os materiais de ensino, pois temos observado que, na formação de professores, esse tema é freqüentemente relegado.

\section{A formação docente}

Nas últimas décadas, as pesquisas envolvendo a sala de aula têm focalizado diferentes aspectos: de professores, currículos, os inúmeros elementos internos ou externos que influenciam a sala de aula e, em menor número, estudos sobre os estudantes. A concepção de que a formação docente - inicial ou contínua - se dá por um acúmulo de cursos, de leituras ou de informações, embora possa ter perdurado por longa data, vem sendo superada. Segundo Gatti (2003, p. 192)

As limitações dessa concepção têm sido tratadas pela pesquisa e literatura em psicologia social, que chamam a atenção para o fato de que esses profissionais são pessoas integradas a grupos sociais de referência nos quais se gestam concepções de educação, de modos de ser, que se constituem em representações e valores que filtram os conhecimentos que lhes chegam. Os conhecimentos adquirem sentido ou não, são aceitos ou não, incorporados ou não, em função de complexos processos não apenas cognitivos, mas socioafetivos e culturais. Essa é uma das razões pelas quais tantos programas que visam as mudanças cognitivas, de práticas, de posturas, mostram-se ineficazes.

Programas ou ações destinados a mudanças na prática dos professores não devem estar apoiados em visões desses profissionais apenas como seres abstratos ou essencialmente intelectuais. É preciso ouvi-los e, para isso, precisamos vê-los na sua complexidade - que inclui sua identidade social, pessoal e profissional - de seres que partilham a vida em grupos sociais, que se relacionam com o outro e com o mundo. Como lembra Gatti (2003, p. 196): 
Promovendo o desenvolvimento profissional na formação...

Há também que se considerar o papel de eventos mais amplos, sejam sociais, políticos, econômicos ou culturais, com seus determinantes que perpassam a vida grupal ou comunitária. Sabemos que a interação desses fatores molda as concepções sobre educação, ensino, papel profissional e as práticas a elas ligadas, concepções e práticas estas que, por sua vez, são estruturalmente delimitadas pela maneira como as pessoas se vêem, como estruturam suas representações, como se descrevem, como vêem os outros e a sociedade à qual pertencem.

Tardif (2002) inclui, no saber docente, características como o estar sempre ligado a uma situação de trabalho com os outros (alunos, colegas, pais etc.), e, além disso, estar ancorado numa tarefa complexa que é o ensino, situado num espaço próprio de trabalho, enraizado numa instituição e numa sociedade. Essas particularidades o situam na interface entre o individual e o social, e essa interface pode ser entendida por meio da análise de diferentes fios condutores, como: o saber e o trabalho, a diversidade do saber, a temporalidade do saber, e a experiência.

Essas categorias assumem maior importância como fundamentos para se pensar a formação de professores, se esta se configura em uma proposta de trabalho colaborativo envolvendo formadores da universidade e professores das escolas. Nessa perspectiva, como pensar os chamados conhecimentos escolares, cuja origem está na elaboração das ciências, das tecnologias, da filosofia e das artes, por exemplo? Como potencializar a reflexão valendo-se de uma base de conhecimentos para o ensino? Gatti (2003), ao tratar do conhecimento, reafirma o seu caráter social:

O conhecimento é enraizado na vida social, expressando e estruturando a identidade e as condições sociais dos que dele partilham. Por isso, ações sociais ou educacionais que têm por objetivo criar condições de mudanças conceituais, de atitudes e práticas precisam estar engrenadas com o meio sociocultural no qual as pessoas, os profissio-nais, que serão abrangidos por essas ações, vivem. (GATTI, 2003, p. 197)

Em síntese, a prática docente é profundamente enraizada no espaço e tempo em que a atuação se dá, assenta-se sobre os saberes do professor, sobre o saber-fazer construído no exercício da docência, sobre quem são os alunos na visão dos professores. Na condução da prática, são elementos importantes as concepções sobre a função da escola para determinado grupo de alunos, assim como as condições de exercício da docência, a pertinência cultural e a visão da profissão e da carreira. Um projeto, programa, ou curso de formação, para atingir seus objetivos, necessariamente há que manter a interlocução com os professores. A opção da discussão neste artigo centra-se na análise da aprendizagem da docência e do desenvolvimento profissional dos professores em uma experiência situada de produção de histórias infantis com conteúdo matemático. 


\section{Material didático e formação docente}

Voltamos ao nosso primeiro questionamento sobre as freqüentes demandas dos docentes acerca de experiências práticas e materiais para o ensino. Encontramos, em Zabala (1998), a afirmação de que, na formação docente, é preciso introduzir ações adaptadas às novas necessidades formativas, que surgem a cada momento. Segundo ele:

O objetivo não pode ser a busca da 'fórmula magistral', mas a melhora da prática. Mas isso não será possível sem o conhecimento e uso de alguns marcos teóricos que nos permitam levar a cabo uma verdadeira reflexão sobre essa prática, que faça com que a intervenção seja a menos rotineira possível, que atuemos segundo um pensamento estratégico que faça com que nossa intervenção pedagógica seja coerente com nossas intenções e nosso saber profissional. (ZABALA, 1998, p. 51)

Dessa forma, partimos da premissa de que não é possível a aprendizagem de uma única fórmula para a atuação em diferentes contextos. Essa é a crítica mais importante aos livros didáticos, pois são organizados na lógica das diferentes matérias e apresentam um resumo dos conhecimentos que geralmente ficam "externos" ao aluno.

Entretanto, há necessidade de que o professor construa um repertório de saberes ou desenvolva o que Zabala (1998) chama de pensamento estratégico, necessários à ação docente. Buscando experiências que, de alguma maneira, contribuem para esse desenvolvimento, temos o trabalho de Davis e Krajcik (2005) sobre o que chamam de materiais curriculares educativos, desenvolvidos tendo como referência os estudos sobre aprendizagem da docência. Segundo eles:

a aprendizagem do professor envolve desenvolver e integrar sua base de conhecimento sobre conteúdo, ensino e aprendizagem, tornar-se capaz de aplicar aquele conhecimento em tempo real e tomar decisões instrucionais, participar dos discursos sobre o ensino, tornandose enculturado em (e engajado em) uma cadeia de práticas de professores. A aprendizagem do professor é situada na prática - inclui a instrução em sala de aula, mas também o planejamento, a reestruturação de aulas, a avaliação, a colaboração com colegas e a comunicação com pais. (DAVIS e KRAJCIK, 2005, p. 3)

Por tratar-se de uma atuação profissional complexa, a formação desse profissional inicial ou contínua - em termos de aquisição de conteúdo específico, vai além do como ensinar; sua formação deve ajudá-lo a desenvolver conhecimentos mais gerais que possam ser aplicados a novas situações. Nesse sentido, a construção de materiais que auxiliem nesse desenvolvimento profissional parece um promissor campo de investigação e de formação.

Ao tratar de materiais curriculares educativos com o objetivo de promover a aprendizagem de professores, Davis e Krajcik (2005) observam que 
Promovendo o desenvolvimento profissional na formação...

tais materiais promoverão aprendizagem entre alguns professores e podem promover o desenvolvimento da disposição para a reflexão em outros. Isso no melhor dos cenários - os materiais curriculares acompanhados de outras ações de desenvolvimento profissional - a incorporação de elementos educativos [de formação] nos materiais curriculares pode aumentar o resultado da aprendizagem como também as melhorias do desenvolvimento profissional. Nós enfatizamos que os materiais educativos curriculares, como qualquer inovação educacional, não servem como panacéia. Entretanto, esses materiais fornecem uma forma de intervenção capaz de dar importante suporte para alguns professores. (DAVIS e KRAJCIK, 2005, p. 4)

Esse alerta é importante, pois a docência é de tal forma complexa que não podemos cair no engodo das soluções milagrosas. A utilização - ou construção - de material pedagógico não pode ser ancorada em uma concepção simplista na qual a formação desse profissional seja substituída por - ou se dê via - "kits" pedagógicos. As reflexões sobre o material didático, na perspectiva desse artigo, estão associadas a um projeto mais amplo de formação docente.

A construção e o uso de materiais didáticos passa, primeiramente, pela concepção sobre o papel dos docentes. Esse tema está vinculado a dois aspectos interligados: a formação de professores e as suas concepções pedagógicas. Miorim e Fiorentini (1990) destacam esse fato quando analisam esta temática, lembrando que a escolha de um material, pelo professor, nem sempre é realizada com a devida clareza quanto a sua fundamentação teórica. De modo geral, enfatizam os autores, sempre que um congresso ou encontro de professor de matemática promove oficinas, conferências a respeito dessa temática, as salas ficam lotadas, evidenciando o grande interesse pelos materiais e jogos. Entretanto, essas discussões, muitas vezes, ficam restritas à utilização de um recurso que se mostrou favorável para a abordagem de um determinado tópico da matemática, não ocorrendo, naquele momento, reflexões de caráter epistemológico.

Precisamos superar a expectativa que muitos professores têm, quando justificam a opção pela utilização de materiais concretos como um fator de motivação, tornando as aulas mais alegres, para que os alunos passem a gostar da matéria.

Ao falar sobre a importância dos materiais concretos na aula de matemática, Miorim e Fiorentini $(1990$, p. 7) salientam que "por trás de cada material se esconde uma visão de educação, de matemática, do homem e de mundo; ou seja, existe, subjacente ao material, uma proposta pedagógica que o justifica". Os autores enfatizam ainda que os professores não "podem subjugar sua metodologia de ensino a algum tipo de material porque ele é atraente ou lúdico [...] nenhum material é válido por si só” (p. 9).

Esse contraponto apresentado pelos autores indica, para a formação de professores, a busca de um equilíbrio entre a teorização da área e a ênfase nos recursos. As concepções de Castelnuovo (1970) podem ser estendidas para a formação de professores ao enfatizar que a idéia fundamental da ação deve ser a reflexão:

que o interesse da criança não seja atraído pelo objeto material em si ou pelo ente matemático, senão pelas operações sobre o objeto e seus 
entes. Operações que, naturalmente, serão primeiro de caráter manipulável para depois interiorizar-se e posteriormente passar do concreto ao abstrato. Recorrer à ação, diz Piaget, não conduz de todo a um simples empirismo, ao contrário, prepara a dedução formal ulterior, desde que tenha presente que a ação, bem conduzida, pode ser operatória, e que a formalização mais adiantada o é também. (CASTELNUOVO, 1970, p. 25)

As pesquisas têm demonstrado a fragilidade do domínio de conhecimento dos conteúdos por parte dos docentes. Antes que nos sintamos tentados a oferecer mais cursos com ênfase na transmissão de conteúdos, os resultados de estudos na área de formação de professores, há muito, levaram à superação da idéia de que se aprende a ser professor e a ensinar por meio de justaposição de conhecimentos ou cursos. Então, como intervir na formação de modo a minorar essa fragilidade teórica?

Há necessidade de se levarem em conta as características do pertencimento cultural, sociais, afetivas e cognitivas, além das condições de exercício da docência para cada profissional e suas questões, dúvidas, problemas. Sendo assim, professores trazem, na bagagem, conhecimentos e perguntas quando procuram um curso de formação contínua.

Perante um conjunto de professores da rede pública paulista atuando nas séries iniciais do Ensino Fundamental, implementamos uma proposta de elaboração de material curricular com o duplo objetivo de aprofundar questões referentes aos conteúdos de matemática e leitura, e promover diferentes ações destinadas ao desenvolvimento profissional dos professores.

A nossa proposta consiste na elaboração de histórias infantis com conteúdo matemático. Tendo em vista a superação dos dilemas aqui levantados, investimos em ações formativas que procuram aliar literatura infantil, leituras, narrativas e conteúdos matemáticos na formação de professores.

\section{A formação docente e materiais de ensino: articulação por meio de narrativas}

Utilizar a narrativa aliada ao processo educativo, em geral, é um meio bastante difundido desde as tradicionais fábulas e entre os apólogos aos livros paradidáticos da atualidade. Tratando de conteúdos matemáticos, ainda na primeira metade do século XX, Monteiro Lobato escreve a sua Aritmética da Emília, fazendo referência a outra obra bastante conhecida: O homem que calculava, de Malba Tahan, pseudônimo de Júlio César de Mello e Souza. Dalcin (2002) pesquisou a importância dos livros paradidáticos para o ensino da Matemática no $3^{\circ} \mathrm{e}$ $4^{\circ}$ ciclo do Ensino Fundamental e, ao se referir às obras de Lobato e Malba Tahan, afirma que "através de suas obras mostraram-nos que a matemática pode ser ensinada por meio de nossa capacidade imaginativa e criativa de contar histórias" (DALCIN, 2002, p. 15).

Smole e Diniz (2001) e Smole et al. (2004) estudam as conexões da literatura infantil e da produção de textos na aula de Matemática. Outros autores, como Bicudo e Garnica (2001), Gómez-Granel (1996), e Teberosky e Tolchinsky (1996), também mostram a importância do trabalho integrado, bem como a aproximação da área da matemática e da língua materna. 
A literatura, por excelência, é um espaço de síntese da experiência humana, das emoções, e, por isso, seu uso tem sido destacado, em diversos estudos, como privilegiado para o trabalho interdisciplinar. O texto, nas aulas de matemática, contribui para a formação de alunos leitores, possibilitando a autonomia de pensamento e, também, o estabelecimento de relações e inferências, com as quais o aluno pode fazer conjecturas, expor e contrapor pontos de vista. Pois, como afirma Smole et al. (2004):

Interrogado pelo texto, o leitor volta a ele muitas vezes para acrescentar outras expectativas, percepções e experiências, desta forma, a história contribui para que os alunos aprendam e façam matemática, assim como exploram lugares, características e acontecimentos na história, o que permite que habilidades matemáticas e de linguagem desenvolvam-se juntas, enquanto os alunos lêem, escrevem e conversam sobre as idéias matemáticas que vão aparecendo ao longo da leitura. É neste contexto que a conexão da matemática com a literatura infantil aparece. (SMOLE et al., 2004, p. 2)

Referindo-se à importância da ficção na infância, Dalcin (2002) afirma que

As narrativas ficcionais mais conhecidas como "histórias" exercem forte influência tanto na formação cognitiva como na afetiva e social da criança. Sejam na forma de antigas lendas, contos de fadas, histórias infantis ou parábolas bíblicas, independentemente do gênero, as narrativas de ficção valorizam e ampliam nossa capacidade imaginativa, desenvolvem várias habilidades e estruturas do pensamento, além de auxiliarem na construção de significados. (DALCIN, 2002, p. 60)

A referida autora enfatiza ainda que, relativamente à Matemática, pode-se dizer que a imaginação tem um importante papel nos processos de compreensão, reflexão e abstração, pela possibilidade de criação de situações particulares vinculadas a outras conhecidas.

Na mesma direção, os estudos de Alton-Lee, Nuthall e Patrick (1999) indicam que as experiências das crianças na construção de conhecimentos caracterizam-se como um processo único envolvendo três fatores concorrentes: a resposta aos tópicos do currículo, o gerenciamento da cultura da classe e a participação nos processos socioculturais.

O termo construção de conhecimento é usado para referir-se a uma unidade do conhecimento que é construída na memória quando a criança interpreta a experiência escolar em relação a um conhecimento anterior. Essa construção envolve a criança em uma série de processos cognitivos: obter informações, criar associações, elaborar o conteúdo, avaliar a veracidade e a consistência da informação e desenvolver conhecimentos metacognitivos (ALTON-LEE, NUTHALL e PATRICK, 1999). O ato de ler e entender a história favorece e potencializa esses processos cognitivos importantes para capacitar a criança a penetrar no estudo da matemática como uma área de conhecimento que exige a compreensão da sua linguagem específica e de raciocínios próprios para a solução de problemas.

Dalcin (2002) salienta que 
Oliveira, R. M. M. A.; Passos, C. L. B.

Por intermédio de histórias infantis, as crianças tomam contato com diferentes situações e realidades. Os personagens, sejam eles humanos, animais, duendes, fadas, bruxas [...] vivenciam conflitos e tomam decisões. Habitam num universo situado em um contexto particular que é regido por regras e normas próprias. Nesse universo, os personagens estabelecem relações entre si e com o seu meio, relações essas que precisam ser conhecidas e compreendidas por quem ouve ou lê a história. (DALCIN, 2002, p. 62)

Dessa forma, entender como a narrativa opera ou qual sua função na vida cotidiana ajuda a entender seu potencial educativo em sentido amplo ou em sentido estrito: sua utilização nas aulas de matemática e seu poder formativo no desenvolvimento profissional de futuros professores.

Inicialmente, é preciso considerar que uma narrativa envolve elementos como: personagens, enredo, espaço, tempo e, sobretudo, a configuração de um conflito relacionado a mudanças na situação que obrigam à reflexão e/ou ação dos personagens. É a resposta a esse conflito que leva ao desfecho do enredo. Sobre os processos da narrativa diferentes autores já se pronunciaram, como por exemplo, Ricoeur apud Bruner (1997) que afirma:

Uma história descreve uma seqüência de ações e experências de um determinado número de personagens, sejam reais ou imaginários. Esses personagens são respresentados em situações que mudam... às quais eles reagem. Essas mudanças, por sua vez, revelam aspectos ocultos das situações e dos personagens, dando lugar a uma nova condição que pede reflexão ou ação, ou ambos. A resposta a esta condição leva a história à sua conclusão. (RICOEUR apud BRUNER, 1997, p. 46)

Essa estrutura da narrativa advém, em grande parte, da tradição, mas como acrescenta Bruner (1997, p. 47-48), é razoável supor que há uma aptidão humana para a narrativa capaz de conservar e elaborar tal tradição: "eu me refiro a uma aptidão ou predisposição para organizar a experiência em uma forma narrativa, em estruturas de enredo e assim por diante".

O autor acrescenta que a essa predisposição para a organização narrativa, "a cultura logo nos equipa com novos poderes de narração, através de seu kit de ferramentas e através das tradições de contar histórias e interpretá-las, das quais nós logo nos tornamos participantes" (BRUNER, 1997, p. 74).

Uma característica crucial da narrativa, segundo Bruner (1997, p. 49), é que ela se especializa em forjar ligações entre o excepcional e o comum. Toda cultura assenta-se no canônico, num conjunto de normas, crenças e comportamentos partilhados. A função da narrativa numa cultura está relacionada à interpretação do excepcional, do incomum, e permite ao narrador lidar simultaneamente com canonicidade e excepcionalidade. Nas palavras do autor: "As histórias atingem seus significados explicando desvios do comum de uma forma compreensível [...]".

Essa característica é valiosa para pensarmos sobre o material narrativo presente nas 
histórias com conteúdo matemático. Cabe-nos indagar: qual sua utilidade? Parece que a resposta a essa questão está relacionada, de alguma forma, ao não canônico, pois esse tipo de narrativa aborda uma temática disciplinar de uma área do conhecimento e integra-a ao discurso narrativo. Permite matematizar o mundo no sentido de tematizar o conteúdo matemático, e desloca a prática docente com esse conteúdo da atitude de passar o ponto, ensinar um conjunto de regras previamente formulado, para a atitude inquieta da pergunta, do conflito narrativo que leva à reflexão, à aposta na postura de descobrir a matemática, mais que na postura de ensinar a matemática que se conhece.

Dalcin (2002) afirma que a Educação Matemática começa a buscar um discurso próprio, aliado à compreensão de que a construção de significados próprios dos alunos, na relação com os significados histórica e culturalmente negociados, passa pela leitura de novos textos relacionados ao conteúdo matemático. Segundo Dalcin (2002),

Sem dúvida, a busca por esse novo discurso da Educação Matemática passa pela necessidade de procurar formas diferentes de relacionar os vários elementos que, de uma forma ou de outra, sempre nele (discurso) estiveram presentes: os símbolos matemáticos, as palavras e as imagens.

O papel das imagens [...] parece fundamental, principalmente no atual momento histórico, no qual as possibilidades tecnológicas ampliaram consideravelmente as suas funções nos mais variados setores da sociedade moderna. (DALCIN, 2002, p. 50-51)

O material didático, seja ele de qualquer natureza, para ter efetivo sucesso na utilização no processo de ensino e aprendizagem deve possuir algumas características fundamentais para permitir a expansão da experiência do aluno e do professor com relação a determinado conhecimento. Deve permitir, ainda, por exemplo, a problematização dos conceitos ou idéias a serem exploradas e novas estratégias de resolução de problemas. É importante que o material forneça esclarecimento sobre um conteúdo problemático ou ofereça pistas para mais pesquisas. Enfim, a construção e a utilização de materiais deve permitir, tanto ao professor como ao aluno, a possibilidade de dar uma significação pessoal ao tema estudado, ao conteúdo trabalhado em qualquer nível ou modalidade de ensino, seja um conhecimento conceitual, um conhecimento procedimental ou atitudinal.

\section{A pesquisa}

A área de formação de professores no Brasil possui uma produção consolidada que pode ser comprovada, por exemplo, pela vasta e rica produção apresentada em congressos nacionais, como na Reunião Anual da Associação Nacional de Pós-Graduação e Pesquisa em Educação (ANPEd), no Encontro Nacional de Didática e Prática de Ensino (ENDIPE) e no Congresso Estadual Paulista de Formação de Educadores (CEPFE). No entanto, são raras as pesquisas envolvendo a análise de processos de construção de materiais didáticos elaborados 
Oliveira, R. M. M. A.; Passos, C. L. B.

por professores ou por futuros professores. Este trabalho tem como finalidade colaborar com essa área ao analisar as contribuições da elaboração de livros infantis com conteúdo matemático para o desenvolvimento profissional de professores.

\section{O contexto}

Participaram do curso objeto dessa investigação quarenta professores ${ }^{3}$ - sendo apenas um do sexo masculino - que, no $2^{\circ}$ semestre de 2005, atuavam em escolas públicas estaduais do interior do Estado de São Paulo. O curso fez parte do programa de formação continuada dentro da política paulista de capacitação de professores denominado Teia do Saber. Foram promovidas ações formativas para o uso dos livros infantis disponíveis nas bibliotecas das escolas, bem como a construção de materiais didáticos, sob a forma de livros infantis com conteúdo matemático.

O curso teve duração de oitenta horas e foi dividido em dois módulos: "Práticas de Leitura na Escola: ler para aprender e comunicar aos outros" e "A produção de livros infantis com conteúdo matemático", envolvendo aprofundamento teórico sobre a linguagem, a diversidade cultural e a maneira como essa diversidade é representada em obras didáticas e em imagens, em geral por meio de leituras, debates, conversas etc.

Os procedimentos utilizados para a produção de livros infantis foram os seguintes:

. Levantamento bibliográfico de produções literárias infantis da escola e análise de suas características;

. Estudo da fundamentação teórica da proposta;

. Escolha de um conteúdo matemático para ser abordado e do enredo da história infantil explicando a sua pertinência no Ensino Fundamental;

- Apresentação da proposta do grupo para toda a turma, com análise e discussões a respeito da sua relevância e possibilidades de execução;

. Estudo e análise da linguagem adequada para a criação dos textos em que os conteúdos matemáticos seriam integrados às histórias infantis;

. Criação de ilustrações para o livro e apresentação de um esboço do livro;

. Realização de pareceres sobre o esboço apresentado por colegas;

. Discussão dos pareceres e elaboração da $2^{\mathrm{a}}$ versão do livro;

. Correção final e elaboração do livro: digitação, impressão e encadernação;

. Apresentação do conjunto de livros produzidos em um seminário ao final do curso;

. Elaboração de um plano de atividades para a aplicação da obra em sala de aula.

No total, foram elaborados 16 livros infantis. Os conteúdos matemáticos abordados pelos professores foram: frações, simetria, formas geométricas, contagem, seqüência e siste-

\footnotetext{
${ }^{3}$ Os professores participantes serão mencionados neste trabalho pela letra $\mathrm{P}$, seguida de número que os identifica.
} 
ma monetário. Os títulos são criativos e relacionam-se a outras áreas do conhecimento, como Viagem ao Egito, que aborda uma viagem a esse país, tratando da geometria das pirâmides e cultura. Outro livro, As estações do ano ensinando simetria, trata, de maneira lúdica, dois temas que aparentemente não têm conexão: estações do ano, trabalhadas em Ciências e Geografia, e a simetria em Matemática.

Duas auxiliares de pesquisa atuaram na coleta de dados realizando registros escritos dos debates, dos relatos dos participantes relativos a situações de sala de aula e das análises externadas para o grupo em diferentes momentos.

Também foram analisados documentos escritos pelos participantes. Foi preenchida uma ficha de dados dos participantes que incluía: dados pessoais, de formação e de atuação docente, e uma questão sobre o que esperava do curso.

No final do curso, durante a apresentação oral dos livros elaborados, cada participante teceu considerações ao processo de desenvolvimento profissional vivido e indicou o uso do livro elaborado em sala de aula do Ensino Fundamental. Esses depoimentos foram gravados em vídeo e transcritos.

Esses dados compuseram o corpus desta investigação, e sua análise permite compreender as perspectivas dos professores sobre a experiência de formação vivenciada.

\section{Os participantes}

Dos quarenta professores participantes deste estudo, 14 (35\%) são habilitados em cursos de nível médio, 23 (57\%) possuem formação no nível superior, dois não responderam e um está cursando o primeiro ano do curso de Letras. Dos professores com curso superior, 13 são licenciados em Pedagogia (desses, um também é licenciado em Educação Física e um em Ciências e Matemática). Há, ainda, professores licenciados em Estudos Sociais e Geografia (um), Estudos Sociais (um), História (um), Educação Física (três), Normal Superior (um), Biblioteconomia e História (um).

A maioria dos participantes (24) tem mais de 15 anos de experiência docente nas séries iniciais, e destes, vinte possuem entre 16 e vinte anos de experiência, três possuem de 21 a 25 anos, e apenas um tem trinta anos de experiência. Cinco docentes possuem entre 11 a 15 anos de experiência e cinco docentes estão na faixa de seis a dez anos de experiência. Seis docentes são iniciantes e possuem entre um a cinco anos de experiência.

Ao elencar as expectativas sobre o curso, 31 professoras indicaram duas categorias principais ligadas à aquisição de conhecimentos e às atividades ligadas à melhoria da prática pedagógica. Dos quarenta participantes, 12 indicaram conjuntamente essas expectativas. Uma das professoras, por exemplo, indicou que desejava que o curso fosse "prático para poder passar aos alunos ensino de qualidade e aumentar conbecimentos" $\left(\mathrm{P}_{3}\right)$, enquanto outra esperava encontrar "novos conhecimentos, melhoria na situação funcional e troca de experiências com os colegas" $\left(\mathrm{P}_{11}\right)$. Os demais professores dividiram-se entre a perspectiva da aquisição de conhecimentos e expectativas diretamente relacionadas à prática pedagógica. Ao se referirem à aquisição de conhecimentos, utilizaram diferentes expressões, como: novos conhecimentos, enriquecer, aprimorar, elevar, acrescentar, ampliar ou melhorar conhecimentos.

Ao se referirem ao aprimoramento da prática pedagógica, os professores utilizaram 
Oliveira, R. M. M. A.; Passos, C. L. B.

expressões indicando preocupação com a troca de experiências entre os pares, expectativa em relação a aprendizagens de novas técnicas, estratégias ou metodologias. A professora $\left(\mathrm{P}_{7}\right)$ parece expressar uma expectativa coletiva ao dizer: "Espero que seja um curso que eu possa praticar, que eu aprenda algo novo para aplicar em sala de aula".

\section{Análise dos participantes sobre a construção dos livros paradidáticos}

Destaca-se o envolvimento dos professores durante todo o curso, por exemplo: quando foi solicitado que trouxessem livros paradidáticos de Matemática para serem analisados pelo grupo, foram trazidos oitenta livros com 42 títulos diferentes. No momento de construção do livro, uma das participantes contou que, durante o sono, sonhava com o livro: "Quando meu marido chegou e bateu à porta, estava dormindo e sonhando. Escutava uma batida e achava que os desenhos geométricos [tema do livro em elaboração] estavam pulando, pulando, pulando [...]” $\left(\mathrm{P}_{18}\right)$.

Destacamos algumas aprendizagens indicadas pelas docentes, como as mudanças nas concepções sobre determinado conteúdo. Uma professora exemplifica como concepções construídas na prática docente foram desestabilizadas a partir de um percurso formativo.

Inicialmente, ela evoca a dificuldade com o tema em sala de aula: "Nós escolhemos este tema [geometria] pela dificuldade que a gente encontra na sala de aula e ele veio justamente auxiliar o nosso trabalho de final de ano. Geralmente, a geometria é uma tarefa de final de ano". ( $\left.\mathrm{P}_{0}\right)$

Em diferentes momentos na discussão coletiva, observamos que a escolha do tema ou o enredo escolhido etc. são referendados pelos pares: "A ausência da geometria eu vejo que não é só nos dias de hoje, mesmo quando nós estudamos, ela já era deixada de lado. Como educador é difícil você passar o conteúdo da geometria porque [fica] só nos conceitos básicos: triângulo, quadrado, círculo e retângulo". $\left(\mathrm{P}_{1}\right)$

É revelada aqui uma tensão entre a compreensão do professor sobre conteúdos específicos (figuras geométricas, no caso) e sobre como eles deveriam ser ensinados para serem compreendidos pelas crianças. Segundo Mizukami (2004, p. 4), "professores bem sucedidos não podem, simplesmente, ter uma compreensão intuitiva ou pessoal de um conceito, princípio ou teoria particular", pois isso não é suficiente para alterar uma prática que as próprias professoras consideram limitada.

O livro referido acima foi construído em dupla e uma das autoras aponta dificuldades na sua elaboração. Notamos que essas dificuldades também estão relacionadas às novas aprendizagens referentes aquele conteúdo matemático: "Ele se chama o 'Uso da geometria'. Não foi fácil fazêe-lo porque a gente acha até que tudo que estápronto é fácil, mas não é fácil trabalhar principalmente a geometria”. ( $\left.\mathrm{P}_{0}\right)$

No final, percebe-se a mudança na concepção sobre o lugar da geometria no ano escolar, e, também, a conseqüente mudança de lugar no currículo quando esse tema assume importância como conteúdo a ser ensinado por professoras que dominam esse assunto: "[a construção do livro] deu uma visão diferente sobre o assunto. A partir de agora ele será trabalhado desde o começo do ano, facilitando realmente o entendimento matemático do dia-a-dia. Foi muito bom. Ajudou a trabalhar esse conteúdo na sala de aula". ( $\left.\mathrm{P}_{0}\right)$

Novamente, a experiência é validada pelos pares: "Os livros de geometria que foram feitos aqui são muito válidos. Abriu a mente, o que uma colega falou do educando, porque você se coloca no lugar, como o educando vê a geometria". $\left(\mathrm{P}_{1}\right)$ 
Como afirma Mizukami (2004, p. 4), ainda que o conhecimento do conteúdo específico (formas geométricas) fosse necessário para o ensino, esse domínio não bastaria, visto que "os professores devem encontrar formas de comunicar conhecimentos para os outros".

A discussão coletiva, o sentimento de pertença a um grupo colaborativo permitiu, em diferentes momentos, a possibilidade de vencerem desafios. Uma docente compartilhou a aversão sobre um conteúdo, analisando como tentou superá-la ao longo da carreira, e o prazer em ter sido desafiada no curso:

"Eu achei super interessante o tema porque eu como aluna sempre tive pavor de trabalhar com fração. Se uma atividade tivesse fração, eu me recusava, [...] eu não vou faz̨er, porque não sei, não entendo. Como professora eu fui obrigada a aprender fração para passar para os alunos. Nunca imaginei, na minha vida, que en fosse estar fažendo um livro que tratasse de frações. Então me realizei!!” $\left(\mathrm{P}_{31}\right)$

O título do livro é sugestivo: Diversão e Fração. Nele essa professora pôde transformar uma aversão, possivelmente causada pela não aprendizagem, em prazer.

Outra mudança importante ocorreu com relação à prática de avaliação dos alunos, segundo uma professora: "Eu aprendi uma coisa nova que eu não sabia, que a gente podia escrever textos em Matemática. A gente tem mania de departamentar os assuntos, não sei se épor causa do livro didático [...] percebi sem prova [avaliação] o que eles sabiam ou não, este modo enriqueceu muito”. ( $\left.\mathrm{P}_{5}\right)$

Quando ela afirma que obteve indicadores da aprendizagem dos alunos por meio de um outro instrumento - a escrita de um texto pessoal - que não a realização de uma prova formal, podemos esperar que essas mudanças na avaliação dos alunos possam provocar também mudanças na avaliação do próprio ensino desenvolvido, como relata outra professora "Eu passei para a classe alguns exercícios sobre frações, depois pedi para eles escreverem sobre o que entenderam e como chegaram ao resultado. Foi muito gratificante, pois observei os alunos que dominaram o assunto e os que ainda estavam com dificuldades. É mais uma possibilidade do professor poder avaliar os alunos e se avaliar". $\left(\mathrm{P}_{19}\right)$

Outras professoras indicam mudanças na compreensão sobre a metodologia adotada nas aulas. Uma docente com 14 anos de experiência também interpreta de forma crítica a sua forma de ensinar em contraposição com a utilização de livros paradidáticos:

"Nos livros paradidáticos os assuntos são apresentados sem cobrança, nem a imposição que muitas vezes eu coloco para os alunos. A própria convocaşão para ler ou ouvir uma história coloca o aluno em estado de atenção, o que pode ou não ocorrer com um tema novo de matemática apresentado por mim, professora, sem o recurso contextualizado de uma história, on uma atividade lúdica". $\left(\mathrm{P}_{22}\right)$

A contextualização presente na história é destacada pela professora, e esse é um elemento que favorece o ensino mais significativo para a criança.

Outra aprendizagem observada foi a possibilidade de um trabalho interdisciplinar. A interdisciplinaridade é difícil de ser ensinada pois é mais uma atitude, como mostra Bochiniak (1992). Temas que extrapolam os limites de uma área de conhecimento são evidenciados quando os professores descrevem o livro elaborado. Oferecem pistas das inúmeras aprendizagens realizadas, inclusive em áreas nas quais o curso não atuou, como, por exemplo, a inclusão, que é explicitada em, pelo menos, duas obras. Outras temáticas, como as diferentes 
culturas, trazem abordagens ricas e criativas, como as relações entre Egito, África, cultura egípcia, pirâmides e geometria, que aparecem na descrição de uma autora:

'Nós trabalhamos também a inclusão, colocamos aí [no livro] uma aluna negra, uma européia, um indio e uma cadeirante [...] O livro começa contando que as crianças foram vencedoras de um concurso de bigiene bucal, outra área na escola [...] as crianças que não sabem escovar os dentes direito [...] a porta de entrada de muitas doenças é a boca. Apresentamos um mapa, o planisfério que tem o Brasile o Egito, que fica no continente africano. A gente fez uma consulta na Internet e apresentou um pouco da história do Egito. A gente vai chegando na matemática de mansinho. Apresentamos uma pirâmide, porque eles vão ver a pirâmide e trabalhar com a figura tridimensional: as faces e a base. Apresentamos aqui uma dobradura que vai formar uma pirâmide [...] sutilmente nós estamos apresentando a matemática. Tem um comentário "a maravilha de ver as pirâmides" outra pesquisa na Internet. Apresentamos uma atividade pra eles verem quantos triângulos tem numa figura. ... eles vão trabalhar a base quadrada e a face triangular [...] os números e escritas egipcias. A gente faz. uma viagem lá na antiguidade apresentando umas figuras do museu do Cairo, também da Internet. As crianças [personagens] vão compartilhando, fazendo a socialização da viagem, [...] e aparece ali o cadeirante e todas as outras crianças reunidas". $\left(\mathrm{P}_{12}\right)$

As diferentes aprendizagens abrangem aspectos relacionados ao conteúdo de ensino, às estratégias para esse ensino e, mais que isso, ao enraizamento na escola pública e seus temas: higiene, inclusão, multiculturalismo, internet etc., que são também temas brasileiros e mundiais do nosso tempo.

\section{A produção de materiais de ensino na formação de professores: redimensionando conhecimentos}

Atualmente, diferentes alternativas de formação passam a considerar aspectos que emergem da prática docente e a conceber os professores como agentes de seu próprio desenvolvimento profissional. O grupo de pares é tratado, por exemplo, como uma comunidade de investigação, no trabalho de Cochran-Smith e Lytle (1999), ou como comunidade de prática, no trabalho de Wenger (2001). Neste estudo buscamos analisar a fala de professores sobre suas aprendizagens quando submetidos a um curso de formação contínua no qual foram desafiados a conectar literatura infantil e matemática.

A construção do livro foi uma experiência que exigiu dos participantes o pensamento crítico em todos os momentos, e algumas aprendizagens puderam ser percebidas.

A concepção de que é difícil estabelecer relações entre a matemática e a língua portuguesa, declarada pelos participantes, foi sendo redimensionada por eles ao longo do processo formativo desenvolvido. O redimensionamento do conhecimento profissional em relação a conteúdos, estratégias de ensino e de avaliação foi possível mediante a combinação de fatores como a reflexão sobre a prática partilhada no grupo, que, em diferentes momentos, estimulou os depoimentos, acatou as diferentes opiniões, referendou posicionamentos e escolhas, aplaudiu conquistas etc. $\mathrm{Na}$ definição do tema matemático, os participantes fugiam de temáticas sobre as quais tinham pouco domínio, e isso só foi possível, no caso da geometria, por exemplo, quando perceberam que era um tema pouco conhecido e explorado por todos. 
Promovendo o desenvolvimento profissional na formação...

Então, puderam compartilhar suas dúvidas e avançar nesse campo. Enfim, a participação no grupo de pares promoveu o desenvolvimento em diferentes domínios.

Outro fator determinante para o redimensionamento de conhecimentos profissionais foi a efetiva participação em uma tarefa que envolvia a interdisciplinaridade e a ação criativa. O curso implicou-os diretamente no processo de autoria de um livro. $O$ fato de precisarem construir um livro que tivesse conteúdo matemático os levou a: pesquisar, adquirir novos conhecimentos, buscar na interlocução com os pares as definições de enredo, personagens etc., negociar a escolha do conteúdo matemático que trouxesse mais resultados, tendo como referência sua prática em sala de aula e seus alunos. As tentativas de aproximar diferentes áreas em um trabalho interdisciplinar, além do acesso a outros conteúdos culturais, a atitudes e valores apontam também possibilidades promissoras de mudanças na prática. $\mathrm{O}$ desenvolvimento profissional dos professores depende de investimento pessoal, e os dados indicam sucesso na mobilização dos participantes para essas ações e satisfação pelos resultados alcançados.

\section{Considerações finais}

Os resultados do estudo permitem analisar uma estratégia de formação contínua de professores que alia histórias infantis e matemática em uma proposta de construção de um livro infantil para ser utilizado como material paradidático no Ensino Fundamental.

Essa experiência guarda semelhanças com a apontada por Davis e Krajcik (2005), quando a criação de um material pensado para ser utilizado na escola com seus alunos favorece tanto a resignificação de conteúdos específicos, como outras possibilidades de desenvolvimento profissional.

O trabalho colaborativo na discussão do currículo escolar deve ser seguido pelas discussões sobre sua implementação. Nesse sentido, a construção de materiais de ensino não pode ser vista como menor ou como capitulação ao tecnicismo pedagógico. Ao contrário, deve ser concebida como etapa fundamental para a consecução dos objetivos educacionais que têm como horizonte a autonomia, o espírito crítico e a solidariedade - na medida em que envolve grupos de professores refletindo e atuando conjuntamente para propor soluções inovadoras para os desafios da nossa escola tão necessitada de espírito criador e de vivências em grupos colaborativos neste século.

\section{Referências}

ALTON-LEE, A.; NUTHALL, G.; PATRICK, J. Reframing classroom research: a lesson from the private world of children. In: MINTZ, E.; YUN, J. T. (Ed.s). The complex world of teaching: perspectives from theory and pratice. Cambridge: Harvard Educational Review, 1999. p. 43-75. [Reprint series, n. 31].

BICUDO, M. A.; GARNICA, A. V. M. Filosofia da Educação Matemática. Belo Horizonte: Autêntica, 2001. 
Oliveira, R. M. M. A.; Passos, C. L. B.

BOCHINIAK, R. A interdisciplinaridade na escola e fora dela. São Paulo: Loyola, 1992.

BRUNER, J. Atos de significação. Porto Alegre: Artes Médicas, 1997.

CASTELnUOVO, E. Didática de la matemática moderna. México: Trillas, 1970.

COCHRAN-SMITH, M.; LYTLE, S. Relationships of knowledge and practice: teacher learning in communities. In: IRAN-NEJAD, A.; PEARSON, C. D. (Eds.). Review of

Research in Education. Washington: AERA, 1999. v. 24. p. 251-307.

DALCIN, A. Um olhar sobre o paradidático de matemática. 2002. 162f. Dissertação (Mestrado em Educação: Educação Matemática) - Faculdade de Educação, Universidade Estadual de Campinas, Campinas, 2002.

DAVIS, E. A.; KRAJCIK, J. Designing educative curriculum materials to promote teacher learning. Educational Researcher, v. 34, n. 3, p. 3-14, 2005.

MIORIM, M. A.; FIORENTINI, D. Uma reflexão sobre o uso de materiais concretos e jogos no Ensino da Matemática. Boletim da SBEM-SP, São Paulo, v. 4, n. 7, p. 5-10, 1990.

GATTI, B. A. Formação continuada de professores: a questão psicossocial. Cadernos de Pesquisa, v. 1, n. 119, p. 191-204, 2003.

GÓMEZ-GRANELL, C. A aquisição da linguagem matemática: símbolo e significado. In: TEBEROSKY, A.; TOLCHINSKY, L. (Orgs.). Além da alfabetização: aprendizagem fonológica, ortográfica, textual e matemática. Trad. Stela Oliveira. São Paulo: Ática, 1996. p. $257-282$.

MIZUKAMI, M. G. Aprendizagem da docência: algumas contribuições de L. Shulman. Educação, Santa Maria, RS, v. 29, n. 2, p. 1-16, 2004. Disponível em: <http:// www.ufsm.br/ce/revista>. Acesso em: 21 jun. 05.

SMOLE, K. C. S. et al. Era uma vez na matemática: uma conexão com a literatura infantil. São Paulo: CAEM/IME/USP, 2004.

SMOLE, K.; DINIZ, M. I. (Orgs.). Ler, escrever e resolver problemas: habilidades básicas para aprender matemática. Porto Alegre: Artmed, 2001.

TARDIF, M. Saberes docentes e formação profissional. Rio de Janeiro: Vozes, 2002.

TEBEROSKY, A.; TOLCHINSKY, L. (Orgs.) Além da alfabetização: aprendizagem fonológica, ortográfica, textual e matemática. Trad. Stela Oliveira. São Paulo: Ática, 1996.

WENGER, E. Comunidades de práctica: aprendizaje, significado e identidad. Espanha: Paidós, 2001.

ZABALA, A. A prática educativa: como ensinar. Porto Alegre: Artmed, 1998.

Artigo recebido em janeiro de 2007 e aprovado em outubro de 2007. 